\title{
CONTRIBUIÇÃO AO ESTLDO DA DISTRIBUIC:ÃO DO APARÊLHO RETICULAR DE GOLGI NOS GÂNGLIOS SIMPÁTICOS DO HOMEM
}

\author{
JosÉ Fernandez *
}

Em 1898 Golgi descreveu, no citoplasma das células nervosas impregnadas com a reação argêntica de sua autoria, uma estrutura em forma de rêde de malhas largas que denominou "aparêlho reticular interno".

Valiosas contribuições sôbre a morfologia e significação do aparêlho de Golgi foram dadas por Cajal e sua escola. O método primitivo de Golgi, a variante de Veratti e a fórmula de Kopsch não são constantes em seus resultados. A fórmula do nitrato de prata reduzido ', em muitas ocasiōes, oferece ótimos resultados. Em 1912, Cajal descobriu uma fórmula excelente para a coloração do aparêlho de Golgi, a qual possui a grande vantagem de ser constante, dando melhores resultados que as anteriores; o sêgredo desta fórmula está na fixação em nitrato de urânio ${ }^{3}$. As investigações de Cajal e sua escola conduziram às seguintes conclusões: o aparêlho de Golgi compóe-se de dois elementos, um sistema de cavidades contínuas, limitadas ou não por uma parede reticular fina, e um conteúdo granuloso cuja massa e distribuição sofrem modificações na dependência do estado fisiológico ou patológico do citoplasma. Conforme o método empregado, coram-se o sistema de cavidades ou as granulações.

As variações da disposição do aparêlho reticular de Golgi, nas diferentes células do organismo, se encontram relatadas nos tratados de citologia, porém não encontramos referências à disposição de citado organóide nas células do sistema simpático, e que justifica, ao nosso ver, a presente nota.

\section{MATERIAL, METODOS E RESULTADOS}

Nosso material compōe-se de 15 gânglios simpáticos humanos ( 3 cervicais superiores, 4 estrelados, 2 torácicos e 6 lombares), de indivíduos entre 25 e 50 anos. As impregnações foram feitas pelo nitrato de prata reduzido de Cajal, e os cortes, cm parafina, foram executados em série (35 cortes de 7 micra, para cada gânglio); estudamos um corte de cada 3 efetuados. O conceito de normalidade foi estabelecido pelo estudo microscópico de cortes

* Professor de Citologia e de Histologia da Faculdade Católica de Filosofia. Assistente da Faculdade de Medicina da Universidade da Bahia e da Escola Baiana de Medicina e Saúde Pública. Patologista da Fundação Octavio Mangabeira. 
de gânglios utilizados em nossas observações, corados pela hematoxilina-eosina, impregnados pelo Bielchowsky e, em alguns casos, corados pelo tricrômio de Gomori. Para contrôle, principalmente com a finalidade de estudar os tipos que Cajal descreveu, utilizamos gànglios raquídeos de gato com 60 dias de idade, impregnados com o nitrato de urânio, empregando, assim, método e material idênticos aos utilizados por Cajal (fig. 1).

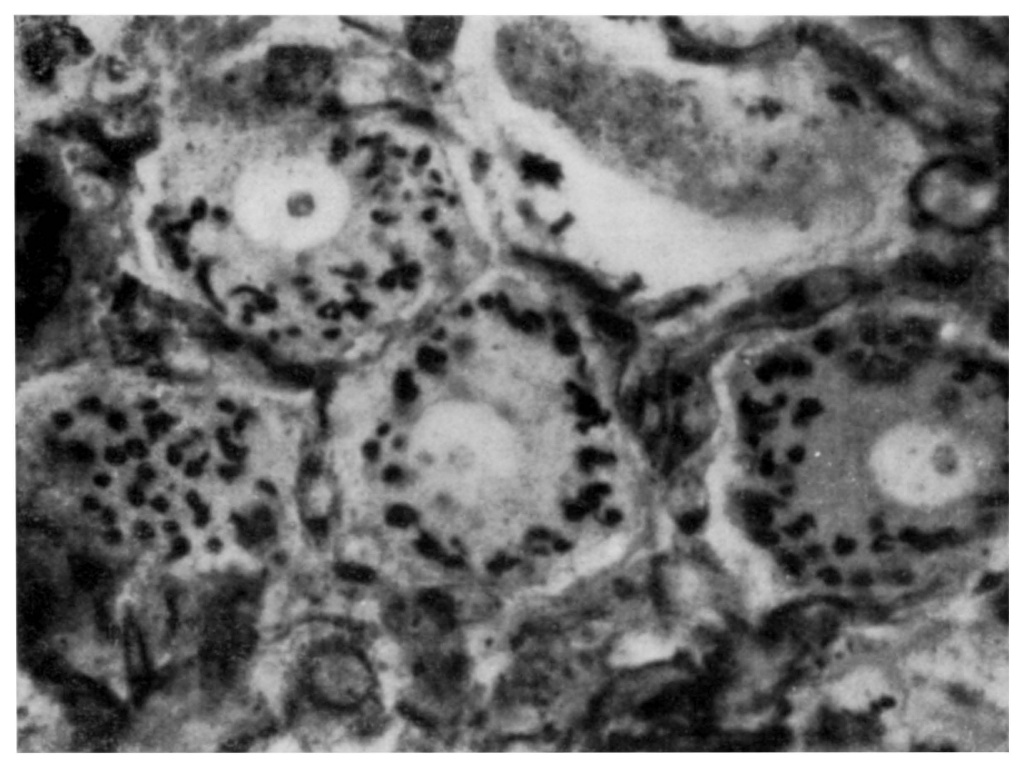

Fig. 1 - Aumento 450x. Método de nitrato de urânio. Gânglio raquídeo de guto. Aparêlho reticular de Golgi que se dispõe em tôrno do núcleo.

Para estabelecer a disposição, do aparêlho de Golgi mais freqüente em gânglios simpáticos humanos, procuramos seguir os tipos descritos por Cajal ao estudar êste organóide em gânglios sensitivos. Entretanto, fomos obrigados a enquadrar nossos resultados em menor número de tipos, tendo sempre como base os de Cajal. Assim procedemos por serem os nossos cortes impregnados pelo método do nitrato de prata reduzido de Cajal, em lugar do de urânio, obtendo-se, com métodos diferentes, resultados distintos. As modalidades por nós observadas podem ser divididas em seis tipos: no primeiro, circunscrito, as granulaçōes do aparêlho reticular se localizam em um dos polos da célula; no segundo, semilunar, as granulações se dispõem formando uma semilua; no terceiro, em ferradura, as granulações estão localizadas em forma mais dispersa qu€ no anterior; no quarto, circular, as granulações se encontram em tôrno do núcleo, envolvendo-o inteiramente; no quinto, com- 
pacto, as granulações se encontram espalhadas por tôda a célula e o núcleo é invisivel; no sexto tipo, oposicional, as granulaşōes se localizam em dois pontos opostos (fig. 2).

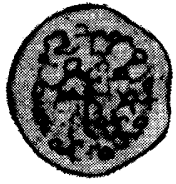

1

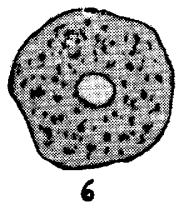

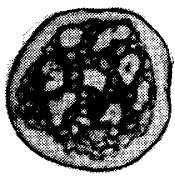

2

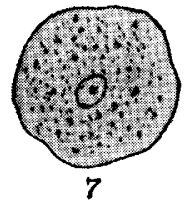

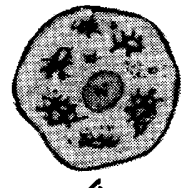

4

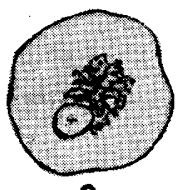

9
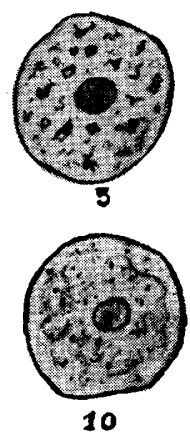

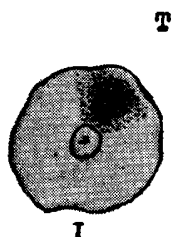

I

T I P $0 \mathrm{~S}$
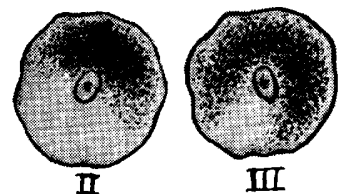

O B S
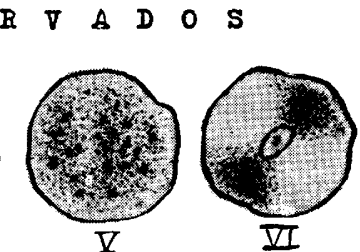

Fig. 2 - Desenhos esquemáticos das modalidades de disposiçuo e distribuição do aparêlho de Golgi: na parte superior, os 10 tipos descritos por Cajal em células de gânglio raquídeo de gato, com o método de nitrato de urânio; na parte inferior, os 6 tipos encontrados em gânglios simpáticos humanos, com o método de nitrato de prata reduzido.

Para estabelecer a percentagem dos diferentes tipos, contamos 100 células para cada caso, fazendo a soma dos elementos de um só campo microscópico para cada corte escolhido; esta operação foi feita utilizando ocular periplana (Leitz-Wetzlar) com aumento de 10 vêzes e objetiva apocromática (Zeiss-Winkel), com aumento de 42 vêzes. O método de iluminação empregado foi o de Kohler.

Nossos resultados acham-se esquematizados no quadro 1 , onde se pode observar a predominância do tipo circunscrito sôbre os demais, vindo em seguida o tipo circular, com menos de metade do valor obtido para o anterior $(35,46 \pm 4,66$ para o circunscrito e $15,13 \pm 2,25$ para o circular, com uma diferença entre os dois de 20,33). Estabelecido o total para cada tipo, calculamos a média, o desvio padrão, o coeficiente de variação percentual, o êrro da média e o cálculo da variância, segundo o método de Student. Notamos que os valores por nós encontrados possuem alta significação estatística (quadro 2) e não são resultado de mera casualidade. 


\begin{tabular}{|c|c|c|c|c|c|c|c|}
\hline & Casos & Tipo I & Tipo $I I$ & Tipo $I I I$ & Tipo $I V$ & Tipo $r$ & Tipo VI \\
\hline 1 & $\ldots \ldots \ldots \ldots \ldots$ & $34 \%$ & $19 \%$ & $12_{i}^{i}$ & $13 \%$ & $18 \%$ & $4 \%$ \\
\hline 2 & $\ldots \ldots \ldots \ldots \ldots$ & $30 \%$ & $15 \%$ & $19 \%$ & $15 \%$ & $12 \%$ & $9 \%$ \\
\hline 3 & $\ldots \ldots \ldots \ldots \ldots$ & $30 \%$ & $17 \%$ & $15 \%$ & $16 \%$ & $14 \%$ & $8 \%$ \\
\hline 4 & $\ldots \ldots \ldots \ldots \ldots$ & $37 \%$ & $14 \%$ & $13 \%$ & $14 \%$ & $15 \%$ & $7 \%$ \\
\hline 5 & $\ldots \ldots \ldots \ldots \ldots$ & $45 \%$ & $11 \%$ & $10 \%$ & $15 \%$ & $12 \%$ & $7 \%$ \\
\hline 6 & $\ldots \ldots \ldots \ldots$ & $44 \because: 0$ & 11 s & $13 \%$ & $21 \%$ & $7 \%$ & $4 \%$ \\
\hline 7 & $\ldots$ & $34 \%$ & $17 \%$ & $14 \%$ & $13 \%$ & $14 \%$ & $8 \%$ \\
\hline 8 & $\ldots$ & $34 \%$ & $9 \%$ & $14 \%$ & $14 \%$ & $25 \%$ & $4 \%$ \\
\hline 9 & $\ldots \ldots$ & $36 \%$ & $16 c_{o}^{\prime}$ & $17 \%$ & $16 \sigma^{\circ}$ & $13 \%$ & $2 \%$ \\
\hline 10 & $\ldots \ldots \ldots \ldots$ & $30 \%$ & $17 \%$ & $19 \%$ & $16 \%$ & $14 \%$ & $4 \%$ \\
\hline 11 & $\ldots \ldots \ldots \ldots \ldots$ & $31 \%$ & 16 ; & $20 \%$ & $17 \%$ & $10 \%$ & $6 \%$ \\
\hline 12 & $\ldots \ldots \ldots \ldots \ldots$ & $35 \%$ & $15 \%$ & $21 \%$ & $14 \%$ & $10 \%$ & $5 \%$ \\
\hline 13 & $\ldots \ldots \ldots \ldots \ldots$ & $35 \%$ & $21 \%$ & $15 \%$ & $13 \%$ & $9 \%$ & $7 \%$ \\
\hline 14 & $\ldots \ldots$ & $42 \%$ & $9 \%$ & $10 \%$ & $18 \%$ & $13 \%$ & $8 \%$ \\
\hline 15 & $\ldots \ldots \ldots \ldots \ldots \ldots$ & $35 \%$ & $16 \%$ & $14 \%$ & $12 \%$ & $8 \%$ & $15 \%$ \\
\hline Tote & $\ldots \ldots \ldots \ldots \ldots$ & 532 & 223 & 226 & 227 & 194 & 98 \\
\hline Méà & $\ldots \ldots \ldots \ldots$ & 35,46 & 14,86 & 15,06 & 15,13 & 12,93 & 6,53 \\
\hline Des & vio padrāo $\ldots . .$. & $\pm 4,66$ & $\pm 3,34$ & $\pm 3,33$ & $\pm 2,25$ & $\pm 4,02$ & $\pm 2,98$ \\
\hline \multicolumn{8}{|c|}{ Coeficiente da variação } \\
\hline & percentual) $\quad \ldots \ldots$. & 13,14 & 22,47 & 22,11 & 14,87 & 31,09 & 45,63 \\
\hline Êrro & o padrão da média. & 1,20 & 0,86 & 0,86 & 0,58 & 1,03 & 0,77 \\
\hline
\end{tabular}

Quadro 1

\begin{tabular}{c|c|c|c|c|c|c|c|c}
\hline Tipos & $n$ & $\bar{x}$ & $s$ & $s^{2}$ & $s d \vec{x}$ & $t$ & $\begin{array}{c}\text { Grau de } \\
\text { liberdade }\end{array}$ & $\begin{array}{c}\text { Valor de } t \\
\text { tabelado a 5\% }\end{array}$ \\
\hline I & 15 & 35,46 & 4,66 & 21,7156 & - & - & - & - \\
II & 15 & 14,86 & 3,34 & 11,1556 & 0,86 & 23,95 & 14 & 2,145 \\
III & 15 & 15,06 & 3,33 & 11,0889 & 0,86 & 23,72 & 14 & 2,145 \\
IV & 15 & 15,13 & 2,25 & 5,0625 & 0,58 & 35,05 & 14 & 2,145 \\
V & 15 & 12,93 & 4,02 & 16,1604 & 1,03 & 21,87 & 14 & 2,145 \\
VI & 15 & 6,53 & 2,98 & 8,8804 & 0,77 & 37,57 & 14 & 2,145 \\
\hline \hline
\end{tabular}




\section{COMENTARIOS}

As mais interessantes disposições do aparêlho de Golgi são observadas nos gânglios do sistema nervoso vegetativo. Golgi foi o primeiro a descrever as modificações encontráveis e referiu-se a uma variedade em que o órgão endocelular se apresenta fragmentado. Variaçōes semelhantes foram descritas por Kopsch (1903). Misch (1903), com o método de Kopsch e abundante material, estudou o aparêlho de Golgi em grande número de gânglios raquídeos de batráquios, répteis, aves e mamíferos, encontrando, de preferência, um tipo francamente reticulado; referiu-se Misch também à modalidade lobulada de Golgi e a diferentes tipos de retículo fragmentado ou desintegrado em uma série de grânulos, salientando que as células situadas na superfície do gânglio geralmente não apresentam aparêlho reticular.

Bergen (1904), com o método do ácido ósmico, estudou as células dos gânglios raquídeos de mamíferos, descrevendo cinco variedades. Collin e Lucien, em 1909, estudando os gânglios raquídeos de várias espécies de mamíferos, comparando as preparações obtidas com o método de Golgi com as obtidas pelo método de Nissl, descreveram duas modalidades de elementos: nas células pequenas a rêde é monolateral com tubos retos e cavernas onde se percebe fina capa marginal; nas células grandes o retículo é difuso e estende-se por quase todo o citoplasma formando finas trabéculas anastomosadas e sinuosas; entre êstes dois tipos fundamentais havia tipos intermediários. Lengendre (1910), estudando os gânglios raquídeos de coelhos com o método de formol-ácido arsenioso, descreveu várias modalidades de disposição do aparêlho reticular.

Cajal (1914)2 ${ }^{2}$, estudando o aparêlho reticular interno de Golgi em animais jovens, descreveu 10 modalidades distintas: reticular simples, reticular composta, lobulada, em ilhas, tigróide, granulosa, retraída, retículo retraído perinuclear, polar e pálida em vias de desintegração (fig. 2); julga Cajal que as células sem aparêlho reticular descritas por Bergen, correspondam, na realidade, a uma fase fisiológica especial, caracterizada pela palidez excepcional das granulaçōes argentafins.

Com o método do nitrato de prata reduzido com fixação em formol e utilizando gânglios simpáticos humanos, observamos que as granulações do aparêlho de Golgi se dispõem mais freqüentemente em um polo da célula (tipo I). Em relação ao tipo V (compacto), poder-se-ia pensar que se trata do tipo IV, em que o corte apanhou a célula em uma orientação tangencial, já que podemos verificar tal exemplo em livros de citologia, como as figuras descritas por De Robertis, Nowinski e Cáez à e por Ortiz-Picón ?. Vale, porém, referir que em corte tangencial poderemos cortar qualquer dos outros tipos em orientação tal que nos ofereça aspecto semelhante (granulações compactas). No tipo circunscrito, se o corte incidir no polo onde se encontram as granulações, teremos o mesmo aspecto que o observado na célula com granulações dispostas em tôrno ao núcleo (tipo IV), sendo impossivel, nestes dois exemplos, dizer se esta ou aquela célula pertence a êste ou aquêle tipo.

Observamos, também, em todos os nossos cortes, elementos nos quais não se notam granulações. Êste fato, referido primeiramente por Bergen, 
e que Cajal explicou como sendo relativo a elementos em estágio fisiológico especial, pode muito bem ser compreendido, em muitas células, se tivermos em mente que se poderiam obter cortes tangenciais de elementos dos tipos I, II, III e VI, nos quais a incidência atinge a parte do citoplasma sem granulações. As impregnações que observamos com o método do nitrato de urânio, utilizando gânglios raquídeos de gato de 2 meses, confirmam o descrito por Cajal com o mesmo material e método, porém o que aqui discutimos, são as modalidades que se observam no gânglio simpático humano com o método de nitrato de prata reduzido, fixação em formol (figs. 3 e 4).

Supondo que o tipo $\mathrm{V}$ não é mais que uma modalidade do tipo IV, somando-se as médias dêstes dois tipos teremos um total de 28,06\% que, mesmo assim, é inferior ao resultado obtido para o tipo I $(35,46 \%)$. Reunindo todos os nossos seis tipos em duas modalidades - uma em que as granulações tendem a ser ou não circunscritas (tipos I, II e VI), e outra em que as granulações tendem a ser ou não dispostas circularmente (tipos III, IV e V, considerando o tipo $\mathrm{V}$ como variação do IV) - teriamos para o primeiro grupo (circunscrito) um total de $56,85 \%$ e para o segundo um total de $43,12 \%$, havendo, conseqüentemente, uma superioridade da disposição circunscrita sôbre a circular, em se tratando de gânglios simpáticos humanos impregnados pelo método do nitrato de prata reduzido.

$O$ aparêlho de Golgi se modifica não só nas células patológicas ${ }^{1}$ como também na dependência dos métodos de coloração empregados ${ }^{6}$. Em nossas observações, os aspectos variam grandemente nos cortes em que usamos nitrato de urânio e gânglio raquideo de gato, dos que foram impregnados pelo nitrato de prata reduzido e usando gânglios simpáticos humanos.

\section{RESUMO}

Relatamos a disposição que toma o aparêlho reticular de Golgi nas células de gânglios simpáticos do homem. Estudamos 15 gânglios simpáticos humanos ( 3 cervicais superiores, 4 estrelados, 2 torácicos e 6 lombares) impregnados com o método do nitrato de prata reduzido após fixação em formol. As figuras morfológicas observadas foram divididas em 6 tipos, tomando como base, em parte, os tipos descritas por Cajal ao estudar o aparêlho de Golgi nos gânglios raquideos: no primeiro tipo ou circunscrito, as granulações do aparêlho de Golgi se localizam em um dos polos da célula; no segundo ou semilunar, as granulações se dispõem formando uma semi-esfera; no terceiro ou em ferradura, as granulações estão localizadas em forma mais dispersa que no tipo anterior; no quarto ou circular, as granulaçōes se encontram em tôrno do núcleo, envolvendo-o inteiramente; no quinto, compacto, elas se encontram espalhadas por tôda a célula, sendo o núcleo invisível; no último tipo ou oposicional, as granulações se localizam em dois pontos opostos.

Foram feitos cortes seriados, de 7 micra, em número de 35 para cada caso. Escolhemos um corte de cada três e contamos 100 elementos em cada caso; encontramos as seguintes percentagens para os 6 tipos considerados:
1) $35,46 \% \pm 4,66$
2) $14,86 \% \pm 3,34$; 3) $15,06 \% \pm 3,33$;
4) $15,13 \% \pm 2,25$;

5) $12,93 \% \pm 4,02$;

6) $6,53 \% \pm 2,98$. Estabelecemos o índice de significação 


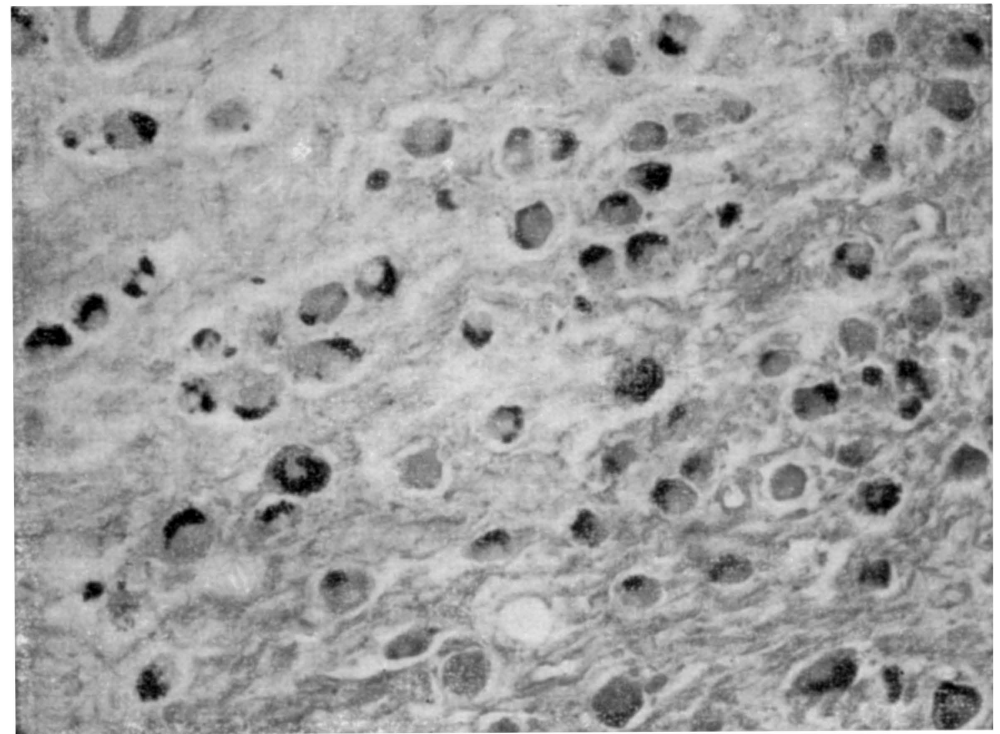

Fig. 3 - Aumento 100x. Método de nitrato de prata reduzido, Aparêlho de Golgi que na maíoria das células se dispõe em um dos polos. Gânglio simpático humano.

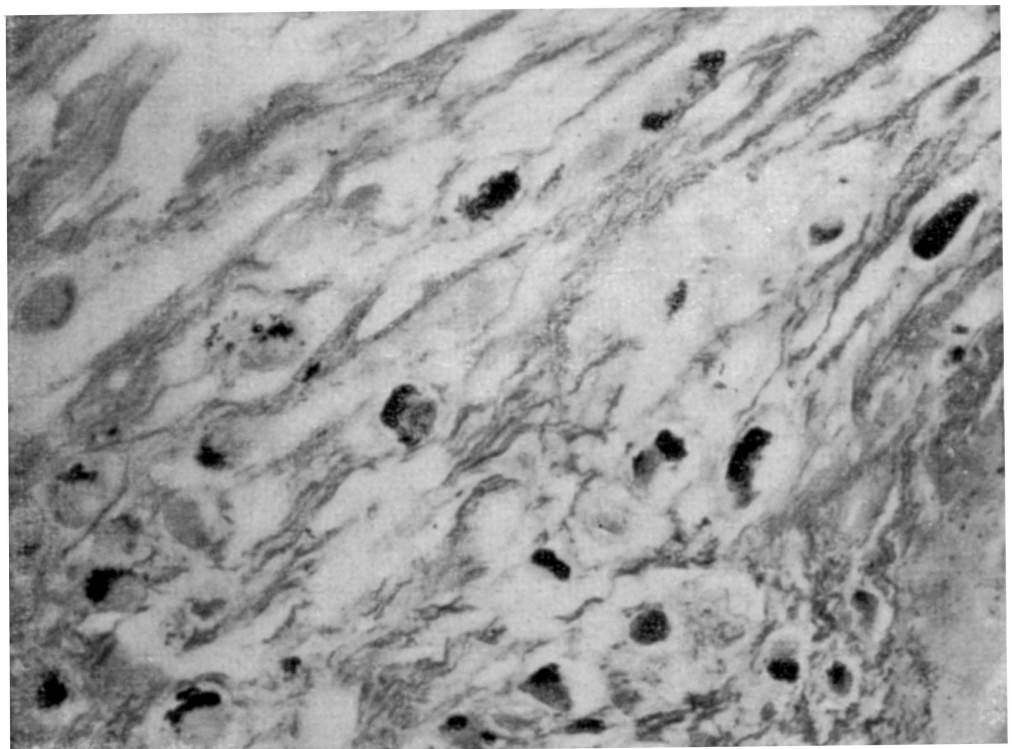

Fig. 4 - Aumento 100x. Método de nitrato de prata reduzido. Aparêlho de Golgi que se revela como pequenas granulacões escuras bem visiveis no citoplasma do neurônio. Ganglio simpático humano. 
utilizando a fórmula de Student, concluindo que os valores encontrados têm significação estatística e não são resultado de mera casualidade.

Como conclusão final, julgamos que nos gânglios simpáticos humanos, utilizando-se o método do nitrato de prata reduzido com fixação em formol, a modalidade circunscrita é o tipo de disposição mais freqüente do aparêlho de Golgi.

\section{SUMMARY}

\section{Contribution to the study of Golgi's reticular apparatus in sympathetic ganglia of man.}

The disposition of Golgi's reticular system in cells of human sympathetic ganglia is reviewed. The author studies 15 human sympathetic ganglia (3 upper cervical, 4 stellate, 2 thoracic and 6 lumbar), impregnated with reduced silver nitrate after formol fixation. The morphologic figures were divided into six types based, in part, on those described by Cajal when studying the Golgi system of spinal ganglia: in the first type (circumscript) the granulations are located in one of the cell poles; in the second (semilunar) they are disposed in the form of a semi-sphere; in the third (horseshoe) they are located like in the second type but in a more sparse form; in the fourth (circular) the granulations surround completely the nucleus; in the fifth (compact) they are scattered all over the cell; in the last type (oppositional) the granulations are located in two opposite spots.

Serial sections of 7 micra were made numbering 35 for each case. The author examined one section out of every 3 and counts 100 elements in each case, finding the following percentages for the 6 considered types: 1) $35.46 \% \pm 4.66$; 2) $14.86 \% \pm 3.34$; 3) $15.06 \% \pm 3.33$; 4) $15.13 \% \pm 2.25$; 5) $12.93 \% \pm 4.02$; 6) $6.53 \% \pm 2.98$. The signification index was established with the Student's formula and the author concludes that the values found bear statistical meaning and are not mere chance results.

The author concludes that, in human sympathetic ganglia, when the reduced silver nitrate method with formol fixation is used, the circumscript form is the most frequently found type of Golgi's system disposition.

\section{REFERENCIAS}

1. BUNO, W. - L'appareil de Golgi de la cellule de Sternberg. Bull. d'Histologie Appliq., 15:5-9, 1938, 2. CAJAL, S. R. - Algunas variaciones fisiológicas y patológicas del aparato reticular de Golgi. Trab. Lab. Univ. Madrid, 12:127-227, 1914. 3. CAJAL, S. R. - Recuerdos de mi Vida. Imprenta Juan Pueyo, Madrid, 1923, págs. 381-382, 4. CAJAL, S. R.; DE CASTRO, F. - Elementos de Técnica Micrográfica del Sistema Nervioso. Tip. Artística, Madrid, 1933, págs. 191 e 192. 5. DE ROBERTIS, E. D.; NOWINSKI, W. W.; SAEZ, F. A. - Citología General. Lib. El Ateneo, Buenos Aires, 2a ed., 1952, pág. 126. 6. GUARDABASSI, A.; TOESCA, G. - L'apparato interno. Analisi comparativa dei risultati ottenuti con tecniche diverse. Arch. Italiano Anat. Embriol., 61:34-57, 1956. 7. ORTIZ-PICON, J. M. - Citología General. Ed. Labor S.A., Barcelona, 1947, págs. 63-69. 